\title{
The relationship between work-related rumination and evening and morning salivary cortisol secretion
}

\section{Mark Cropley ${ }^{*}$, Leif W. Rydstedt ${ }^{2}$, Jason Devereux, J.J ${ }^{3}$ and Benita Middleton ${ }^{4}$}

${ }^{1}$ School of Psychology, University of Surrey, Guildford, Surrey, GU27XH, UK; email: mark.cropley@surrey.ac.uk

${ }^{2}$ Department of Psychology, Lillehammer University College (HiL), AHS, Lillehammer, Norway, email: leif.rydstedt@hil.no

${ }^{3}$ Business Psychology Unit, University College London, UK, email: Jason@wrulds.com

${ }^{4}$ Division of Biochemistry \& Physiology, Faculty of Health \& Medical Sciences, University of Surrey, UK, email: b.middleton@surrey.ac.uk

Running Head: Work-related rumination and cortisol secretion

Key words: Cortisol, CAR, Work-Related Rumination, Anticipation

*Correspondence to: Mark Cropley, School of Psychology,

University of Surrey, Guildford, Surrey, GU27XH

$\dagger$ Email:mark.cropley@surrey.ac.uk

Acknowledgments: The authors would like to thank Jessica Hornsby, Hannah Lewis, \&

Kayleigh Pemberton for their help in collecting the data for this project. 


\begin{abstract}
The perseverative cognition hypothesis suggests that worry/ruminative thinking prolongs stress-related physiological activation. This study explored the association of work-related rumination with salivary cortisol sampled at 10pm, and the cortisol awakening response (CAR) the following morning. On a mid-week evening, 108 school teachers completed a small diary about their work related thoughts and gave a saliva cortisol sample at $10 \mathrm{pm}$. The following morning, they gave four additional saliva samples: at awakening and at 15, 30 and 45 minutes after awakening, along with a rating of their anticipatory thoughts about work. The CAR was calculated as the percentage increase in cortisol secretion from awakening to 30 minutes, and the sample was divided at their respective medians to classify participants into low and high rumination groups. Cortisol secretion was found to be significantly greater in the high compared to the low ruminators at $10 \mathrm{pm}$, and this effect was not related to leisure activities or work patterns during the evening. For the morning measures, high ruminators demonstrated a flattened CAR relative to the low ruminators and this effect appeared to be associated with sleep disturbance during the night. Ruminating about work-related issues is associated with cortisol secretion, and our findings support the perseverative cognition hypothesis.
\end{abstract}




\section{Introduction}

Theories and research on stress have typically focused on the acute stressful event and the strategies individuals employ to cope with the stressor when it occurs. Physiological activation in response to stress is thought to contribute to health and disease. Evidence is starting to emerge however to suggest that the pathway between stress and disease is mediated via the prolonged activation of the stress response (Linden, Earle, Gerin, \& Christenfeld, 1997; McEwen, 1998).

Unwinding following energy expenditure is necessary for physical and psychological recovery as persistent failure to unwind is thought to be detrimental to health because it wears down the body's physiological restorative system (McEwen, 1998). Recovery has been defined as the psycho-physiological unwinding after effort expenditure at work (Geurts \& Sonnentag, 2006) and adequate recovery prevents the accumulation of fatigue (Meijman and Mulder, 1998; Querstret \& Cropley, 2012; Zijlstra \& Sonnentag, 2006). A number of authors have suggested that the speed and completeness of recovery may be as important in the aetiology of disease and illness as the acute reactivity in response to the stress exposure (Linden, et al., 1997; Ursin \& Eriksen, 2004; Brosschot, Pieper, \& Thayer, 2005).

The 'sustained activation theory' (Ursin \& Murison, 1983; Ursin \& Eriksen, 2001; 2004) suggests that when the hypothalamus-pituitary-adrenal HPA axis and sympatheticadrenergic-medullary (SAM) axis are persistently active, recovery does not occur. The repeated activation of the HPA axis and SAM axis can cause lasting neuro-endocrine changes and as a result cause health problems (Wüst, Federenko, Hellhammer, \& Kirschbaum, 2000; De Vente, Olff, Van Amsterdam, Kamphuis, \& Emmelkamo, 2003). In order for a physiological stress response to be prolonged, a cognitive representation of a stressor needs to be activated (Ursin \& Eriksen, 2001). Enduring cognitive processes such as worry, rumination and anticipatory stress have been identified as mediating the process between stress and disease and as such have been termed 'perseverative cognition' (Brosschot, van Dijk, \& 
Thayer, 2002). Perseverative cognition is characterised by repetitive thoughts that are intrusive and contain representations of a past or future anticipatory stressor (Brosschot, Gerin, \& Thayer, 2006). Therefore when individuals engage in perseverative thinking about stressors this initiates or prolongs their physiological stress response, which over time can lead to somatic disease (Brosschot et al., 2005).

\section{HPA Activity Biomarkers of the Stress Response}

An important biomarker for stress responsivity is cortisol secretion. When an individual is presented with a stressful event the HPA axis responds by activating corticotrophin releasing factor $(\mathrm{CRF})$ and adrenocorticotropic hormone $(\mathrm{ACTH})$ neurons in the paraventricular nucleus (PVN). This causes the adrenal cortex to release the stress hormone cortisol. The HPA axis response will vary depending on the psychological components of the situation, for example if the situation is uncontrollable or unpredictable a greater degree of activation may occur (Hellhammer, Wüst, \& Kudielka, 2009).

Cortisol reactivity has been associated with a number of health indices including, cardiovascular disease risk factors (Wallerius et al., 2003), cognitive functioning (Marin, Lord, Andrews, Juster, Sindi, et al., 2011), depression (Huber, Issa, Schik, \& Wolf, 2006), somatic disorders (Tak, Cleare, Ormel, Manoharan, Kok, Wessely, et al., 2011), and upper respiratory infection (Cohen, Hamrick, Rodriguez, Feldman, Rabin, et al., 2002). It is clear that cortisol is therefore an important hormone that plays a major role in a multitude of health related problems and is essential to proper body functioning.

Cortisol secretion exhibits a stable diurnal pattern peaking within the first 30-45 minutes on awakening, and then declining over the day. The initial sharp rise in cortisol on awakening, known as the cortisol awakening response (CAR), is a distinct feature of the 
diurnal pattern of cortisol secretion, and is considered as a marker or indicator of the integrity of the HPA axis (Pruessner, Kirschbaum, \& Hellhammer, 1995; Clow, Thorn, Evans, \& Hucklebridge, 2004; Clow, Hucklebridge, Stalder, Evans, \& Thorn, 2010). Although the timing of the CAR varies across studies, a CAR peaking approximately 30 minutes post awakening is considered to reflect a healthy cortisol circadian rhythm (Clow, Hucklebridge, \& Thorn, 2010). Deviations of the magnitude of the CAR are associated with a number of psychosocial factors in important ways, thus providing an indicator of HPA axis function and dysfunction. The CAR appears to be sensitive to different psychological demands, and has frequently been used as a measure of stress. In particular the CAR has been considered to be a marker of anticipatory stress (Gaab, Rohleder, Nater, \& Ehlert, 2005; Fries, Dettenborn, \& Kirschbaum, 2009; Rohleder, Beulen, Chen, Wolf, \& Kirschbaum, 2007; Preuss, Schoofs, Schlotz, \& Wolf, 2010).

The CAR has also been shown to be associated with sleep, although the research evidence is somewhat equivocal (Garde, Karlsson, Hansen, Persson, \& Åkerstedt, 2011). A recent review identified that the most consistent result is a positive association between longer sleep duration and salivary cortisol at awakening when assessed by a single measure (Kumari, Badrick, Ferrie, Perski, Marmot, \& Chandola, 2009; Stalder, Hucklebridge, Evans, \& Clow, 2009; Hsiao, Yang, Ho, Jow, Ng, et al., 2010). A recent study of 387 Danish civil servants however found that sleep disturbance reported during the previous month was associated with increased morning cortisol secretion at 30 minutes after awakening, and sleep disturbance was associated with a flattened CAR three months later (Hansen, Thomsen, Kaergaard, Kolstad, Kaerlev, et al., 2012).

Although the short-term effect of variations of the CAR are advantageous as cortisol release is thought to prepare the body for impending daily demands, the long-term impact of a dysregulated or blunted CAR can result in permanent changes in the body leading to disease in the long term. This may be due to the mechanisms which underlie the CAR becoming 
exhausted due to constant and prolonged activation. In a systematic review and meta-analysis, Chida and Steptoe (2008) reported that fatigue, exhaustion and burnout are characterised by a reduced CAR. Prolonged HPA activity is associated with atrophy of neurons in the hippocampus, a region of the brain that has been associated with episodic, declarative, and spatial memory (Uno, Tarara, Else, Suleman, \& Sapolsky, 1989; McEwen, 2000). The effects of the mediators of stress such as the HPA axis is best described by the concept of allostatic load which refers to 'the cumulative effects, or the price the body pays for being forced to adapt to various psychosocial challenges and adverse environments' (McEwen \& Seeman, 1999).

Another important marker or indicator of the integrity of the HPA axis is the dynamic feature of cortisol release over the remaining day. Reaching a nadir late in the evening at approximately 10pm (Kirschbaum \& Hellhammer, 1989; Kudielka, Schommer, Hellhammer, \& Kirschbaum, 2004), cortisol release naturally declines across the day but regulation can also be imposed by external factors such as demands, threats, or by restorative activities such as relaxation. Thus, sampling secretion during the nadir also provides an insight in the HPA axis activity (Miller, Chen, \& Zhou, 2007). Low evening cortisol values are considered as an important aspect of a healthy cortisol pattern and assessing cortisol release in the late evening has recently gained more research attention (Rydstedt, Cropley, Devereux, \& Michalianou, 2009, Eek, Karlson, Garde, Hansen, \& Orbæk, 2012).

\section{The Current Investigation}

In line with the thesis that physiological stress responses are modulated by cognitive mechanisms, and that prolonged activation of physiological stress responses through cognitive processing (e.g. rumination) results in a dysregulation of the HPA axis (Brosschot et al., 2002; McEwen, 2002), the aim of the present study was to examine possible associations between cortisol secretion, and perseverative cognition. As reported above, perseverative 
cognition refers to mental representations of a stressful event/s, such as worrisome anticipation prior to, or ruminative thinking following a stressful event. In keeping with this definition, we operationalised perseverative cognition in the present study as ruminative thinking about work-related issues during (i) the evening, following a demanding work day, and (ii) anticipatory stress as thinking/ruminating about work issues in the morning prior to work on awakening. Cortisol was assessed from saliva in order to assess the activity of the HPA axis. Saliva provides a reliable, valid and a non-invasive access to cortisol secretion and cortisol secreted in saliva is known to correlate highly with 'free' cortisol concentration in the blood (Kirschbaum \& Hellhammer, 1989), and is a recommended method of assessing HPA axis activity (Hellhammer et al., 2009). It was predicted that:

(H1) Individuals engaging in high levels of post work-related rumination during the evening will show elevated cortisol secretion at 10pm, relative to low ruminators.

It has been suggested that awakening results in the activation of neocortical networks, which are linked with the reactivation of memory representations residing in the neocortical circuits. The arousal of memory representations in the process of awakening may bring to the preconscious level information that may stimulate the HPA axis (Wilhelm, Born, Kudielka, Schlotz, Wüst, 2007; Chida \& Steptoe, 2008; Fries et al., 2009). Therefore, employees who are worrying about work the previous evening may have these memories reactivated at preconscious levels when they wake-up, thus causing an increase in the CAR. Evidence tentatively supporting this idea has come from patients with severe global amnesia. Patients with severe amnesia have been found not to exhibit the CAR despite showing normal circadian cortisol profiles (Wolf, Fujiwara, Luwinski, Kirschbaum, \& Markowitsch, 2005). In addition, in a study of ballroom dancers, researchers found individuals to show an enhanced CAR on competition days but a normal CAR on non-competition days (Rohleder et al., 2007). Similar results have been found in other studies (Salvador, 2005). Thus, the increase in cortisol secretion appears to be in response to the body preparing itself for the demands of the 
impending day. The anticipation of the impending day may therefore be the crucial mechanism underlying the relationship between psychosocial variables and the CAR. It was further predicted that:

(H2) Individuals who engage in high levels of anticipatory work-related rumination on awakening, will show an elevated CAR, in the morning relative to low ruminators.

\section{Method}

\section{Participants}

Participants were full-time teachers recruited from primary and secondary schools in the UK. Teaching is recognized to be a highly stressful and demanding occupation, and a high proportion of teachers ruminate about work-related issues post work (Cropley \& Millward Purvis, 2003; Cropley, Dijk, \& Stanley, 2006). Thirty-five school heads were contacted by email or by telephone explaining the nature of the research and those who expressed an interest were sent letters of invitation to distribute to their class teachers. Interested teachers then contacted the researchers direct for an information/sample pack, and a free post envelope in which to return their saliva samples and diaries. One hundred and thirty-two packs were sent out, and $123(91 \%)$ were returned within the study period. Fifteen packs however contained no, or missing saliva samples and therefore these were excluded from the analysis. The final sample consisted of 108 participants. Their age ranged from $21-61$ years with a mean age of $40.8(10.45)$ years, and the majority, $71.1 \%$ of the sample were female. The mean number of years at their present school was 8.3 years, and the average number of hours worked per week was 42.4 .

\section{Measures}

\section{Work-related rumination}

The work rumination and sleep questions were incorporated into a small diary that was completed on a workday evening at 10pm. Five evening work rumination questions were 
used: (1) 'Did you think about work in the last hour?' (2) 'Did you think about future work, e.g. lessons, tomorrow?' (3) 'Did you think about things that had happened at work today or before today?' (4) 'Would you describe your work-related thoughts in the last hour as repetitive/recurring?' (5) 'Were your work related thoughts intrusive'. Each was rated on a seven-point scale ranging from $1=$ not at all (intrusive) to $7=$ all the time (intrusive). These questions are similar to those used in previous studies that have investigated work-related rumination (Cropley \& Millward Purvis, 2003; Cropley et al., 2006). Participants were required to indicate their choice by circling an appropriate number. The internal consistency (Cronbach's $\alpha$ ) of the rumination measure was good $=0.91$. In addition, participants reported how much time they spent on the following activities during the evening: (1), Work related activities, (2), Social activities, (3), Household/childcare activities, (4), Physical activities, (5), Low effort activities, and (6), Creative activities \& hobbies. Finally participants reported how stressful their day was using a single item measure rated on a seven-point scale ranging from $1=$ not at all stressful to $7=$ very stressful.

\section{Sleep}

As sleep has been associated with cortisol, upon awakening, participants reported how long they had slept and whether they had been purposefully awoken during the night, e.g. because of childcare duties or telephone calls etc. They also completed the Karolinska Sleep Diary (Åkerstedt, Hume, Minors, \& Waterhouse, 1994), which contains a series of sleep quality questions: (1) 'did you sleep throughout the night' (2) 'was it difficult or easy to fall asleep' (3) ‘did you wake up early’ (4) ‘did you wake up easily’ (6) ‘did you dream' (7) ‘how refreshed did you feel in morning upon waking' (8) 'how well did you sleep' and (8) 'was your sleep restless or calm'. These questions were rated on a seven-point scale with the lower 
number indicating poorer sleep. Following Eek and colleagues (Eek et al., 2012), two indices of sleep were calculated: Disturbed Sleep and Ease of Awakening. The disturbed sleep score was calculated as the mean score of four items relating to (i) difficulties falling asleep; (ii) disturbed/restless sleep; (iii) repeated awakenings; and (iv) premature awakenings (Cronbach's $\alpha=.68$ ), and the ease of awakening score was calculated as the mean score for three items relating to (i) ease of awakening; (ii) whether the respondent felt well rested; and (iii) subjective sleep quality (Cronbach's $\alpha=.67$ ). Additionally, participants gave a rating of their anticipatory ruminative thoughts about work on awakening ("Did you think about work today as soon as you woke up this morning?') using the same 7 - point rating scale as used in the evening.

\section{Cortisol Assays}

Saliva cortisol levels were measured in duplicate, if volume was sufficient, by radioimmunoassay adapted from Read, Fahmy, and Walker (1977). Limit of detection was $0.7 \mathrm{nmol} / \mathrm{L}$, intra-assay coefficient of variation was $10.8 \%, 8.8 \%$ and $5.3 \%$ at $3.3 \mathrm{nmol} / \mathrm{L}, 6.4$ $\mathrm{nmol} / \mathrm{L}$ and $24.7 \mathrm{nmol} / \mathrm{L}$ respectively and inter-assay variation was $11.0 \%, 10.8 \%$ and $10.7 \%$ at $2.5 \mathrm{nmol} / \mathrm{L}, 5.1 \mathrm{nmol} / \mathrm{L}$ and $26.4 \mathrm{nmol} / \mathrm{L}$. The duplicate mean cortisol concentration was used in all analysis.

\section{Procedure}

Participants were instructed to choose a mid-week evening, either a Tuesday or Wednesday to complete their measures, because rumination declines over the working week as most people start to psychologically unwind as the weekend approaches. They were instructed to complete the evening diary at $10 \mathrm{pm}$, and give their saliva sample in a prelabelled tube at this time. 
Participants were asked to refrain from activities when giving their samples that would affect their cortisol levels such as brushing their teeth, drinking fruit juice or caffeinated drinks. The following morning they were asked to give a further four saliva samples in prelabelled tubes: on waking and then, 15, 30 and 45 minutes after waking. They then completed the short morning diary about their sleep and answered the single item concerning their anticipatory ruminative thoughts on awakening. All measures were then posted back to the laboratory together with a cover sheet given details of demographic information, medicine intake, and caffeine consumption.

\section{Data analysis}

The data was divided at their respective medians to create low and high groups for evening rumination and for the morning rumination groups. Univariate analyses of variance (ANOVAs) were conducted to determine the main effects of rumination on evening cortisol secretion. The morning cortisol values were analyzed as (i), the mean cortisol concentration (nmol/l) at the four time points, and (ii), the relative awakening response (defined as the percentage increase between the first and the third (morning peaking at 30 minutes) sample (CAR).

\section{Results}

The means, standard deviations, and correlations of the study variables are presented in Table I. As expected there was a significant positive correlation between evening rumination and morning rumination. Evening rumination was correlated with disturbed sleep and difficulty awakening, that is, high rumination was associated with poorer sleep. Both disturbed sleep and poor ease of awakening was correlated with higher morning anticipatory ruminative thoughts. 
High evening ruminators reported their day to be more stressful compared to the low ruminators $(t=7.89, \mathrm{p}<0.001)$. In regards to the evening activities, preliminary analysis revealed that high ruminators spent a greater proportion of their evening on work related activities relative to low ruminators (108 vs. 53 minutes, $\mathrm{t}=4.56, \mathrm{p}<0.001)$, whereas low ruminators spent a greater proportion of their time on social activities ( 28 vs. 9 minutes, $t=$ 2.27, $\mathrm{p}<0.001$ ), and low effort activities (107 vs. 76 minutes, $\mathrm{t}=3.03, \mathrm{p}<0.001)$. The time spent on exercise and creative activities/hobbies during the evening was insufficient to make meaningful comparisons between the groups. There was no significant difference in the number of minutes spent on household activities (63 vs. 60 minutes), nor was there a significant difference in caffeine and alcohol consumption between the two groups. There were no significant gender differences in rumination or cortisol, and age was not significantly correlated with rumination or cortisol.

\section{INSERT TABLE I ABOUT HERE}

\section{Evening Cortisol}

There was a significant effect of rumination on evening cortisol secretion $(F=5.86, \mathrm{p}<0.02)$. This was due to higher cortisol values in the high relative to the low ruminating group (2.81 vs. $2.10(\mathrm{nmol} / \mathrm{l}))$. The above analysis was repeated controlling for the number of minutes worked over the evening but this did not significantly change the pattern of the overall results $(F=4.85, p=0.05)$. Thus, the first hypothesis was supported.

\section{Morning Cortisol}


Mean cortisol concentrations are presented in Figure 1. There was no significant main effect of group $(F=0.17$, n.s. $)$. However there was a significant effect of time $(F=6.32, \mathrm{p}<0.001)$, and a significant group $\mathrm{x}$ time interaction $(F=2.98, \mathrm{p}<0.05)$. Further inspection of Figure 1 revealed that the interaction was due to a significantly higher concentration of cortisol secretion at 30 minutes in the low relative to the high, ruminators. When the analysis was repeated controlling for sleep quality in terms of disturbed sleep or ease of awakening, the differences between the groups were no longer significant. Thus, the effect appears to be due to the high ruminators experiencing a poorer night's sleep. High ruminators awoke 18.2 minutes earlier than the low ruminators $(\mathrm{p}<0.05)$ and they also reported a more disturbed sleeping pattern and frequent awakenings $(\mathrm{p}<0.05)$ relative to the low ruminators. The final set of analysis examined the CAR response. The percentage increase in cortisol concentration from awakening to 30 minutes was significantly greater in the low ruminators $(81.6 \%)$ compared to the high ruminators $(42.7 \%)(\mathrm{p}<0.05)$. Thus, while both groups appear to demonstrate an increase in cortisol from awakening to 30 minutes, high ruminators had a significantly flattened CAR relative to the low ruminators. Therefore, the second hypothesis was not supported.

\section{INSERT FIGURE 1 ABOUT HERE}

\section{Discussion}

The need for recovery has been identified as the crucial link between stress exposure and illness/disease; and it has been argued that it is not the immediate stress response that is damaging to health but rather the prolonged activation of the stress response system via the HPA axis (Brosschot et al., 2002; McEwan, 2002). Perseverative cognition is thought to perpetuate the stress response and prevent recovery (Brosschot et al., 2002). The current 
investigation examined the role of perseverative cognition, operationalized as work-related rumination, on HPA axis activity in terms of salivary cortisol secretion.

The results supported our primary hypothesis that compared with low ruminators; people high on rumination would exhibit higher evening cortisol. This finding is entirely consistent with previous research (Rydstedt et al., 2009), and is in accord with the principles of perseverative cognition. The secondary hypothesis was more tentative as previous research has been equivocal. Our findings demonstrated that both high and low ruminators demonstrated an increase in cortisol secretion 30 minutes following awakening. It was evident however the interaction was due to a flattening of the CAR in high ruminators. Indeed, the percentage increase between awakening and 30 minutes in the high ruminators was only $42 \%$.

The pattern of high evening cortisol levels and then a flattened CAR is not at first easy to explain, as the findings seem somewhat contradictory. However, our interpretation of the results is that both findings can be fully explained by normal HPA axis activity. Primarily, reacting to the threat of stress by producing greater amounts of cortisol in the evening is consistent with a healthy cortisol pattern. In this instance, the stressor is not immediately present but is the result of ruminating about a past or future threat. By simply recalling a previous stressful experience, an individual will encounter the same levels of physiological arousal that originally accompanied the stressor (Glynn, Christenfeld, \& Gerin, 2007). High ruminators also reported their working day to be more stressful than the low ruminators. Stressors encountered during the day continue to effect HPA axis regulation and cortisol secretion during the evening, as it is mediated by work-related thoughts. In the morning, we interpret the flattened CAR to be the result of sleep disturbance and earlier awakening. The disruption of sleep, as a result of work stress is thought to alter the CAR, causing bursts of cortisol to be secreted before actually waking and therefore reflecting a diminished CAR (Chida \& Steptoe, 2008). Our findings are also consistent with previous research (Morgan, Cho, Hazlett, Coric, \& Morgan, 2002; Dahlgren, Kecklund, \& Åkerstedt, 2005), showing that 
daily work stress was associated with increased evening cortisol secretion, but also a flattened morning cortisol profile. Interestingly a study by Kumari and colleagues, showed evening cortisol secretion to be higher in those who reported short sleep and a high frequency of sleep disturbances (Kumari et al., 2009). Thus, although seemingly contradictory, our findings are logical and consistent with previous research.

It is not known however whether the present findings were influenced by long term stress exposure. In a large meta-analysis that examined HPA axis activity and chronic stress it was found that chronic stress was associated with a diminished CAR but high evening levels of cortisol (Miller et al., 2007). There are now a number of studies that report chronic strain and stress exposure to be associated with elevated evening cortisol concentrations (AardalEriksson, Eriksson, \& Thorell, 2001; Rydstedt, Cropley, Devereux, \& Michalianou, 2008; 2009; Rydstedt, Cropley, Devereux, 2011). It is possible that some of our participants were experiencing chronic stress and future research should examine the longitudinal effects of stress, rumination and cortisol secretion on health.

The current investigation was limited by some methodological constraints. Firstly, we were unable to objectively identify the actual time of awakening and this could have affected our results, although we simply do not know if high ruminators are less accurate than low ruminators in their reports of waking time. In addition, it was not possible to identify when participants gave their saliva samples. Adherence to instructions to collect samples at specific times can be poor and slight deviations from the protocol can result in substantial changes in the CAR (Broderick, Arnold, Kudielka, \& Kirschbaum, 2004). Previous research has shown that men and women differ in their cortisol levels and diurnal rhythmicity and their physiological reaction to the long-term effects of job strain (Van Cauter, Leproult, Kupfer, 1996, Rydstedt et al., 2008). We found no gender differences and this was possibly due to the underrepresentation of males in the sample. A larger sample would also provide the opportunity to examine gender differences in cortisol secretion. In addition, although saliva 
cortisol responses appear closely associated with plasma cortisol (Kirschbaum \& Hellhammer, 1994), it needs to be acknowledged however that saliva cortisol can only be considered as an indicator of endocrine reactivity in the present study.

Another limitation is that only one item was used to assess work-related thoughts in the morning. It would be interesting to examine in greater detail the type of thoughts individuals engage in when they awake in the morning. For some, anticipating work could be a positive activity, as individuals may see the forthcoming day as challenging and rewarding and not as a stressor. Thus, some workers may see their day as a positive challenge while others may see it more of a demand or threat. Anticipating an upcoming demand has been shown to be associated with the CAR (Fries et al., 2009). Finally, we did not assess other forms of rumination, and it is possible that some people may have ruminated about other non-work matters/stressors, and this could have influenced the present results.

\section{Conclusion}

Daily stressors mediated via work-related thoughts continue to effect HPA axis regulation and cortisol secretion during leisure time. Engaging in perseverative work-related thoughts outside work appears to delay physiological recovery as evidenced by greater HPA axis regulation and cortisol secretion during the evening. Disengaging from work-related thoughts outside of the work-place appears to be crucial for restitution and well-being as the inability to recover from stressors may lead to the development of illness/disease long-term. 


\section{REFERENCES}

Aardal-Eriksson, E., Eriksson, T.E., \& Thorell, L.H, (2001). Salivary cortisol, post-traumatic stress symptoms, and general health in the acute phase and during 9-month follow-up. Biological Psychiatry, 15(50), 986-993.

Åkerstedt, T., Hume, K., Minors, D., \& Waterhouse, J. (1994). The meaning of good sleep: a longitudinal study of polysomnography and subjective sleep quality. Journal of Sleep Research, 3(3), 152-158.

Broderick, J.E, Arnold, D., Kudielka, B. M., \& Kirschbaum, C. (2004). Salivary cortisol sampling compliance: comparison of patients and healthy volunteers. Psychoneuroendocrinology, 29(5), 636-650.

Brosschot, J. F., Gerin, W., \& Thayer, J.F. (2006). The perseverative cognition hypothesis: A review of worry, prolonged stress-related physiological activation, and health. Journal of Psychosomatic Research, 60(2), $113-124$.

Brosschot, J.F., Pieper, S., \& Thayer, J.F. (2005). Expanding stress theory: prolonged activation and perseverative cognition. Psychoneuroendocrinology, 30, 1043 - 1049.

Brosschot, J.F., van Dijk, E., \& Thayer, J.F. (2002). Prolonged autonomic activation, perseverative negative cognition, and daily stressors. International Congress Series 1241, $329-336$.

Chida,Y., \& Steptoe, A. (2008). Cortisol awakening response and psychosocial factors: A systematic reviews and meta-analysis. Biological Psychology, 80(3), 265-278.

Clow, A., Thorn, L., Evans, P., \& Hucklebridge, F. (2004). The awakening cortisol response: Methodological issues and significance. Stress, 7(1), 29 - 37.

Clow, A., Hucklebridge, F., Stalder, T., Evans, P., \& Thorn, L. (2010). The cortisol awakening response: More than a measure of HPA axis function. Neuroscience \& Biobehavioral Reviews, 35(1), 97-103. 
Clow, A., Hucklebridge, F., \& Thorn, L. (2010). The cortisol awakening response in context. International Review of Neurobiology. 93;153-175.

Cohen, S., Hamrick, N., Rodriguez, M.S., Feldman, P.J., Rabin, B.S., \& Manuck, S.B. (2002). Reactivity and vulnerability to stress-associated risk for upper respiratory illness. Psychosomatic Medicine, 64(2), 302-310.

Cropley, M., \& Millward Purvis, L.J. (2003). Job strain and rumination about work issues during leisure time: A diary study. European Journal of Work and Organizational Psychology, 12(3), 195-207.

Cropley, M., Dijk, D.J., \& Stanley, N. (2006). Job strain, work rumination, and sleep in school teachers. European Journal of Work and Organizational Psychology, 15(2), 181 196.

Dahlgren, A., Kecklund., G., \& Åkerstedt, T. (2005). Different levels of work-related stress and the effects on sleep, fatigue and cortisol. Scandinavian Journal of Work Environment \& Health, 31(4), 277-285.

De Vente, W., Olff, M., Van Amsterdam, J.G., Kamphuis, J.H., \& Emmelkamo, P .M. (2003). Physiological differences between burnout patients and healthy control: blood pressure, heart rate, and cortisol responses. Occupational Environmental Medicine, 60(1), $54-61$.

Eek, F., Karlson, B., Garde, A.H., Hansen, A.M., \& Orbæk, P. (2012). Cortisol, sleep, and recovery - Some gender differences but no straight associations. Psychoneuroendocrinology, 37(1), 56-64.

Fries, E., Dettenborn, L., \& Kirschbaum, C. (2009). The cortisol awakening response (CAR): Facts and future directions. International Journal of Psychophysiology, 72(1), 67-73.

Gaab, J., Rohleder, N., Nater, U.M., \& Ehlert, U. (2005). Psychological determinants of the cortisol stress response: the role of anticipatory cognitive appraisal. Psychoneuroendocrinology, 30(6), 599-610. 
Garde, A.H., Karlsson, B., Hansen, Å.M., Persson, R., \& Åkerstedt, T. (2011). Sleep and salivary cortisol. The role of salivary cortisol in health and disease. Bentham [ebook] Vol 4, pp. 116-128.

Geurts, S.A.E., \& Sonnentag, S, (2006). Recovery as an explanatory mechanism in the relation between acute stress reactions and chronic health impairment. Scandinavian Journal of Work Environment \& Health,32(6),482-492.

Glynn, L.M., Christenfeld, N., \& Gerin, W. ( 2007). Recreating cardiovascular responses with rumination: The effects of a delay between harassment and its recall. International Journal of Psychophysiology, 66(2), 135-140.

Hansen, Å.M., Thomsen, J.F., Kaergaard, A., Kolstad, H.A., Kaerlev, L., Mors, O., Rugulies, R., Bonde, J.P., Andersen, J.H., \& Mikkelsen, S. (2012). Salivary cortisol and sleep problems among civil servants. Psychoneuroendocrinology, 37(7):1086-95.

Hellhammer, D.H., Wüst, S., \& Kudielka, B.M. (2009). Salivary cortisol as a biomarker in stress research. Psychoneuroendocrinology 34(2), 163 -171.

Hsiao, F.H., Yang, T.T., Ho, R.T.H., Jow, G.M., Ng, S.M., Chan, C.L.W., Lai, Y. M., Chen, Y.T., \& Wang, K.C. (2010). The self-perceived symptom distress and health-related conditions associated with morning to evening diurnal cortisol patterns in outpatients with major depressive disorder. Psychoneuroendocrinology 35(4), 503-515.

Huber, T.J., Issa, K., Schik, G., \& Wolf, O.T. ( 2006). The cortisol awakening response is blunted in psychotherapy inpatients suffering from depression. Psychoneuroendocrinology, 31(7), 900-904.

Kirschbaum, C., \& Hellhammer, D.H. (1994). Salivary cortisol in psychoneuroendocrine research—recent developments and applications. Psychoneuroendocrinology 19(4), $313-333$.

Kirschbaum, C., \& Hellhammer, D.H. (1989). Salivary cortisol psycho-biological research: An overview. Neuropsychobiology, 22(3), 150-169. 
Kudielka, B.M., Schommer, N.C., Hellhammer, D.H. \& Kirschbaum, C. (2004). Acute HPA axis responses, heart rate and mood changes to psychosocial stress (TSST) in humans at different times of day. Psychoneuroendocrinology 29(8), 983-992.

Kumari, M., Badrick, E., Ferrie, J., Perski, A., Marmot, M., \& Chandola, T. (2009). Selfreported sleep duration and sleep disturbance are independently associated with cortisol secretion in the Whitehall II study. The Journal of Clinical Endocrinology \& Metabolism, 94(12), 4801-4809.

Linden, W., Earle, T.L., Gerin, W., \& Christenfeld, N. (1997). Physiological stress reactivity and recovery: conceptual siblings separated at birth? Journal of Psychosomatic Research, 42(2), 117-135.

Marin, M.F., Lord, C., Andrews, J., Juster, R.P., Sindi, S., Arsenault-Lapierre, G., Fiocco, A.J., \& Lupien, S.J. (2011). Chronic stress, cognitive functioning and mental health. Neurobiology Learning \& Memory, 96(4), 583-95.

McEwen, B.S. (2000). The neurobiology of stress: From serendipity to clinical relevance. Brain Research, 886(1-2), 172-189.

McEwen, B.S.( 2002). Protective and damaging effects of stress mediators: the good and bad sides of the stress response, Metabolism, 51(6 Suppl), 2 -4.

McEwen, B.S. (1998). Protective and damaging effects of stress mediators. New England Journal of Medicine, 338(15),171-179.

McEwen, B.S., \& Seeman, T. (1999). Protective and damaging effects of mediators of stress: Elaborating and testing the concepts of allostasis and allostatic load, Annals of the New York Academy of Sciences, 896, 30-47.

Meijman, T.F., \& Mulder, G.( 1998). Psychological aspects of workload. In: Drenth, P.J.D., Thierry, H., de Wolff, C.J (Eds.), Handbook of work and organizational psychology: Vol. 2 Work Psychology. Hove: Psychology Press, pp.5-33. 
Miller,G.E., Chen, E., \& Zhou, E.S. (2007). If It Goes Up, Must It Come Down? Chronic Stress and the Hypothalamic-Pituitary-Adrenocortical Axis in Humans. Psychological Bulletin. 133(1), 25- 45.

Morgan III, C.A., Cho, T., Hazlett, G., Coric, V., \& Morgan, J. (2002). The impact of burnout on human physiology and on operational performance: A prospective study of soldiers enrolled in the combat diver qualification course, Yale Journal of Biological Medicine, $75(7), 199-205$.

Pruessner, J. C., Kirschbaum, C., \& Hellhammer, D. (1995). Waking up-the first stressor of the day? Free cortisol levels double within minutes after awakening, Journal of Psychophysiology, 9, 365 .

Preuss, D., Schoofs, D., Schlotz, W., \& Wolf, O.T. (2010). The stressed student: influence of written examinations and oral presentations on salivary cortisol concentrations in university students, Stress 13(3), 221-229.

Querstret, D., \& Cropley, M., (2012). Exploring the relationship between work-related rumination, sleep quality and work-related fatigue. Journal of Occupational Health Psychology, 17(3), 341-353.

Read, G.F., Fahmy, D.R., \& Walker, R.F. (1977). Determination of cortisol in human plasma by radioimmunoassay. Use of the 125I-labelled radioligand. Annals of Clinical Biochemistry, 14(6), 343-349.

Rohleder, N., Beulen, S.E., Chen, E., Wolf, J.M, \& Kirschbaum, C. (2007). Stress on the dance floor: the cortisol stress response to social-evaluative threat in competitive ballroom dancers. Personality and Social Psychology Bulletin, 33, 69-84.

Rydstedt, L.W., Cropley, M., \& Devereux, J.J. (2011). Long-term impact of role stress and cognitive rumination upon morning and evening saliva cortisol secretion. Ergonomics, $54(5), 430-435$. 
Rydstedt, L.W., Cropley, M., Devereux, J.J., \& Michalianou, G. (2008). The relationship between long-term job strain and morning and evening saliva cortisol secretion among white-collar workers. Journal of Occupational Health Psychology, 13(2), 105-113.

Rydstedt, L.W., Cropley, M., Devereux, J.J., \& Michalianou, G. (2009). The effects of gender, long-term need for recovery and trait inhibition-rumination on morning and evening saliva cortisol secretion. Anxiety Stress \& Coping, 22(4), 465-474.

Salvador, A. (2005). Coping with competitive situations in humans. Neuroscience \& Biobehavioral Reviews, 29(1), 195-205.

Stalder, T., Hucklebridge, F., Evans, P., \& Clow, A. (2009). Use of a single case study design to examine state variation in the cortisol awakening response: Relationship with time of awakening. Psychoneuroendocrinology, 34(4), 607-614.

Tak , L.M., Cleare, A.J., Ormel, J., Manoharan, A., Kok, I.C., Wessely, S., \& Rosmalen, J.G. (2011). Meta-analysis and meta-regression of hypothalamic-pituitary-adrenal axis activity in functional somatic disorders. Biological Psychology, 87(2), 183-194.

Uno, H., Tarara, R., Else, J.G., Suleman, M.A., \& Sapolsky, R.M. (1989). Hippocampal damage associated with prolonged and fatal stress in primates. Journal of Neuroscience, 9(5),709-1711.

Ursin, H., Murison, R. (Eds.), (1983). Biological and Psychological Basis of Psychosomatic Disease.Oxford: Pergamon Press.

Ursin, H., \& Eriksen, H.R., (2001). Sensitization, subjective health complaints, and sustained arousal. Annals of the New York Academy of Sciences, 8, 933, 119-129.

Ursin, H., \& Eriksen, H.R. (2004). The cognitive activation theory of stress. Psychoneuroendocrinology, 29, 567-592.

Van Cauter, E., Leproult, R., Kupfer, D.J. (1996). Effects of gender and age on the levels and circadian rhythmicity of plasma cortisol. The Journal of Clinical Endocrinology \& Metabolism, 81(7), 2468-2473. 
Wallerius, S., Rosmond, R., Ljung, T., Holm, G., \& Björntorp, P. (2003). Rise in morning saliva cortisol is associated with abdominal obesity in men: a preliminary report. Journal of Endocrinological Investigation, 26(7), 616-619.

Wilhelm, I., Born, J., Kudielka, B.M., Schlotz, W., Wüst, S. (2007). Is the cortisol awakening rise a response to awakening? Psychoneuroendocrinology, 32(4), 358 -366.

Wolf, O.T., Fujiwara, E., Luwinski, G., Kirschbaum, C., \& Markowitsch., H.J. (2005). No morning cortisol responses in patients with seer global amnesia. Psychoneuroendocrinology, 30(1),101 - 105.

Wüst, S., Federenko, I., Hellhammer, D.H., \& Kirschbaum, C. (2000). Genetic factors, perceived chronic stress and the free cortisol response to awakening. Psychoneuroendocrinology, 25(7), 707 -720.

Zijlstra, F.R.H., \& Sonnentag, S. (2006). After work is done: Psychological perspectives on recovery from work. European Journal of Work and Organizational Psychology, 15(2), 129-138. 
Table 1

Means (M), standard deviations (SD), and correlations of the study variables 


\begin{tabular}{|c|c|c|c|c|c|c|c|c|c|c|c|c|c|c|c|c|}
\hline Variable & $\mathrm{M}(\mathrm{SD})$ & 1 & 2 & 3 & 4 & 5 & 6 & 7 & 8 & 9 & 10 & 11 & 12 & 13 & 14 & 15 \\
\hline 1 Evening Rumination & $45(144)$ & _ & & & & & & & & & & & & & & \\
\hline 2. $\quad$ Disturbed Sleep & $5.0(1.35)$ & $-.27 * *$ & - & & & & & & & & & & & & & \\
\hline 3. Ease of Awakening. & $4.5(1.21)$ & $-.54 * *$ & $.59 * *$ & - & & & & & & & & & & & & \\
\hline $\begin{array}{l}\text { 4. Work related activities } \\
\text { (mins) }\end{array}$ & $80.6(71.3)$ & $.44 * *$ & -.09 & -.34 & - & & & & & & & & & & & \\
\hline $\begin{array}{l}\text { 5. Household/childcare } \\
\text { Activities (mins) }\end{array}$ & $61.5(47.0)$ & .07 & -.16 & -.04 & $.21 *$ & - & & & & & & & & & & \\
\hline 6. Social activities (mins) & $18.5(42.0)$ & $-.21 *$ & .12 & .12 & $.21 *$ & -.11 & - & & & & & & & & & \\
\hline $\begin{array}{l}\text { 7. Physical activities } \\
\text { (mins) }\end{array}$ & $14.2(26.1)$ & -.08 & .19 & .13 & $.19^{*}$ & -.32 & .14 & - & & & & & & & & \\
\hline $\begin{array}{l}\text { 8. Low effort activities } \\
\text { (mins) }\end{array}$ & $91.6(52.9)$ & $-.32 * *$ & .09 & .19 & $.26^{*}$ & .06 & -.05 & -.04 & - & & & & & & & \\
\hline 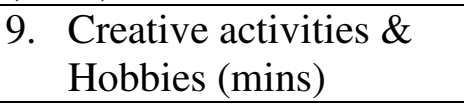 & $2.59(10.1)$ & -.05 & .00 & -.12 & -.18 & -.07 & $.36^{*}$ & .18 & -.07 & - & & & & & & \\
\hline $\begin{array}{l}\text { 10. Morning Rumination } \\
\text { (Anticipation) }\end{array}$ & $4.12(1.9)$ & $.44 * *$ & $-.23^{*}$ & $.26 * *$ & .15 & -.13 & -.03 & .00 & -.15 & -.14 & - & & & & & \\
\hline 11. Evening Cortisol & $2.45(1.56)$ & .10 & -.08 & -.08 & .07 & .06 & $\begin{array}{c}- \\
0.05\end{array}$ & .06 & -.11 & .00 & .00 & - & & & & \\
\hline 12. Awakening Cortisol & $\begin{array}{l}13.45 \\
(7.32)\end{array}$ & .01 & .03 & .13 & -.06 & -.07 & .02 & -.02 & .02 & -.09 & .08 & .10 & - & & & \\
\hline 13. Cortisol at 15 mins & $\begin{array}{l}17.10 \\
(7.24)\end{array}$ & .02 & .12 & .16 &.-02 & -.08 & -.37 & -.08 & -.13 & -.11 & .07 & -.07 & $.64 * *$ & - & & \\
\hline 14. Cortisol at $30 \mathrm{mins}$ & $\begin{array}{l}19.22 \\
(9.25)\end{array}$ & .00 & .18 & .16 & .07 & $\begin{array}{c}- \\
.19^{*}\end{array}$ & -.00 & -.03 & -.14 & -.03 & .02 & .05 & $.46^{*}$ & $.66^{* *}$ & - & \\
\hline 15. Cortisol at $45 \mathrm{mins}$ & $\begin{array}{l}17.91 \\
(7.10) \\
\end{array}$ & -.00 & .07 & .07 & .09 & -.04 & -.10 & -.13 & -.13 & -.08 & .02 & -.04 & $.28 * *$ & $.55^{* *}$ & $.64^{*}$ & - \\
\hline
\end{tabular}


Figure 1 Mean (nmol/l) and standard error of cortisol at awakening and 15, 30 and at 45 minutes in high and low ruminators 


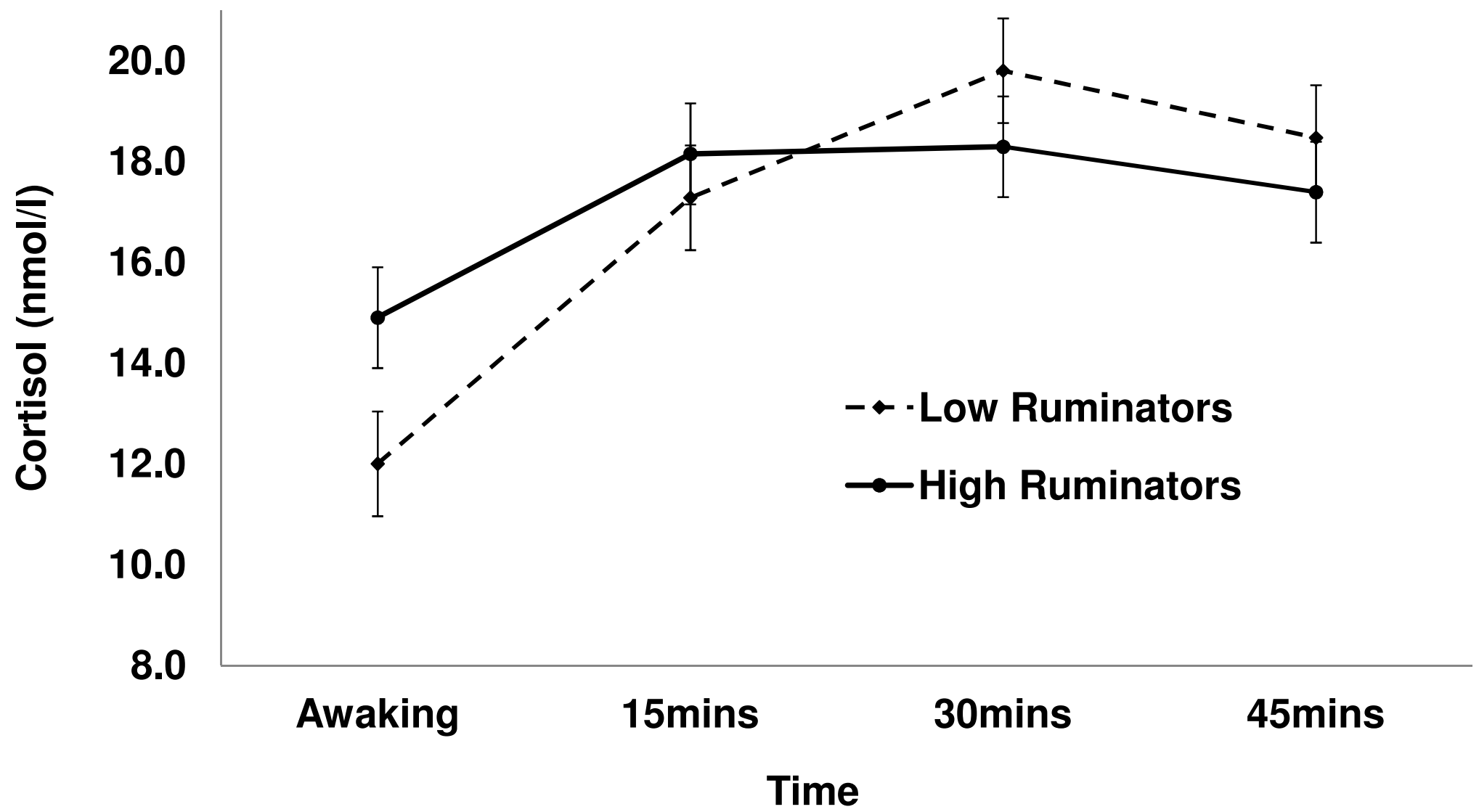

